\title{
PENILAIAN MUTU DOSEN TERHADAP TRI DHARMA PERGURUAN TINGGI DENGAN MENERAPKAN LOGICA FUZZY LOGIC DI STIKES NAN TONGGA
}

\author{
Tri Monarita Johan ${ }^{1)}$, Renty Ahmalia ${ }^{2)}$ \\ ${ }^{1,2}$ STIKes Nan Tongga \\ Email: trimonaritajohan@gmail.com
}

\begin{abstract}
Tri Dharma of Higher Education is an activity that must be carried out by every Lecturer. In this study an application was designed to apply Fuzzy logic to calculate the quality value of Lecturers on the implementation of Higher Education Tri Dharma. Higher Education has the aim of producing quality qualifications. Therefore we need competent teaching staff needed. The background of this research is to study the results obtained from the application and calculation using Fuzzy logic, also help the lecturer evaluation in the field of quality control. The Mamdani Method is often also known as the Max-Min Method. This method was introduced by Ebrahim Mamdani in 1975. To get results, four stages are needed: 1. The formation of the fuzzy set; 2. Application function implications (rules); 3. Composition of rules; 4. Affirmation (deffuzy). The results obtained in this study the value of the function that has been optimized where lecturers will get the best in performance. Data collection methods in the fuzzy inference system function meeting, the author requires input data consisting of three variables and one output variable. Input variables consist of: 1. Research Variables 2. Dedication Variables 3. Teaching Variables. 4. Functional Position Variables After calculations and experiments, the results obtained using the Fuzzy Mamdani method with Matlab.
\end{abstract}

Kata kunci : Fuzzy Mamdani, Matlab, Tri Dharma

\begin{abstract}
ABSTRAK
Tri Dharma Perguruan Tinggi merupakan kegiatan yang harus dilakukan oleh setiap Dosen Pada penelitian ini dirancang aplikasi untuk menerapkan logika Fuzzy untuk perhitungan nilai mutu Dosen terhadap pelaksanaan Tri Dharma Perguruan Tinggi. Perguruan Tinggi memiliki tujuan menghasilkan lulusan-lulusan yang berkualitas. Oleh sebab itu dibutuhkan tenaga pengajar yang berkompeten dalam pengajaran. Tujuan penelitian ini ingin mengetahui hasil yang didapat dari penerapan dan perhitungan menggunakan logika Fuzzy, juga membantu evaluasi Dosen pada bidang pengendali mutu. Penelitian ini bertujuan menerapkan Metode Mamdani untuk mendapatkan nilai optimasi fungsi dengan cepat dalam penilaian kinerja dosen. Metode Mamdani sering juga dikenal dengan nama Metode Max-Min. Metode ini diperkenalkan oleh Ebrahim Mamdani pada tahun 1975. Untuk mendapatkan output, diperlukan 4 tahapan: 1. Pembentukan himpunan fuzzy;2. Aplikasi fungsi implikasi (aturan);3. Komposisi aturan;4. Penegasan (deffuzy). Hasil yang diperoleh : nilai fungsi yang telah teroptimasi dimana akan didapat dosen yang terbaik dalam kinerja. Metode Pengumpulan Data dalam penentuan fungsi keanggotaan fuzzy inference system, penulis membutuhkan data input yang terdiri dari tiga variabel dan satu variabel output. Variabel input terdiri dari : 1. Variabel Penelitian 2. Variabel Pengabdian 3. Variabel Pengajaran. 4. Variabel Jabatan Fungsional Setelah dilakukan perhitungan dan percobaan, maka didapatlah hasil menggunakan metode Fuzzy mamdani dengan Matlab.
\end{abstract}

Kata kunci : Tri Dharma; Fuzzy Mamdani; Matlab 


\section{PENDAHULUAN}

Dosen adalah pendidik profesional dan ilmuwan dengan tugas utama mentransformasikan mengembangkan dan menyebarluaskan ilmu pengetahuan, teknologi, dan seni melalui pendidikan, penelitian, dan pengabdian kepada masyarakat (UU No. 14 Thn 2005 dan PP No. 37 Thn 2009). Tugas utama dosen tersebut adalah melaksanakan Tri Dharma Perguruan Tinggi dengan beban kerja paling sedikit sepadan dengan 12 (dua belas) SKS dan paling banyak 16 (enam belas) SKS pada setiap semester sesuai dengan kualifikasi akademik. Pelaksanaan tugas utama dosen ini perlu dievaluasi dan dilaporkan secara periodik sebagai bentuk akuntabilitas kinerja dosen kepada para pemangku kepentingan.

STIKes Nan Tongga selalu berupaya dalam peningkatan mutu internal secara berkelanjutan. Salah satu upaya yang sudah dilakukan adalah dengan melakukan penilaian terhadap kinerja dosen. Penilaian dilakukan setiap akhir semester dengan membagikan kuesioner penilaian kinerja dosen kepada mahasiswa. Proses penilaian tersebut masih dilakukan secara manual sehingga membutuhkan waktu pengolahan data yang sangat lama. Selain itu penilaian tersebut masih bersifat subjektif dan tidak relevan dengan keadaan yang sebenarnya, sehingga tidak digunakan sebagai dasar pengambilan keputusan (Khoiriyah, 2013).

$\begin{array}{cr}\text { Dalam suatu } & \text { perguruan } \\ \text { tinggi, keberadaan } & \text { dosen }\end{array}$

merupakan salah satu faktor yang dianggap mutlak adanya. Dosen merupakan penunjang utama yang berinteraksi langsung dengan mahasiswa. Seorang dosen dianggap berkualitas apabila dia berhasil dalam kegiatan belajar mengajar. Keberhasilan biasanya diukur dari tingkat keberhasilan dosen dalam mengajar, tingkat kedisiplinan dalam mengajar, kemampuan berinteraksi dengan mahasiswa serta masih banyak faktor lainnya sebagai pendukung. Dosen dituntut untuk dapat memperlihatkan kinerja yang baik. Dalam penilaian kinerja dosen aspek yang dinilai adalah aspek yang terkait tridarma perguruan tinggi.

Pada penelitian ini, penulis bermaksud melakukan penerapan logika Fuzzy pada aplikasi penilaian mutu Dosen terhadap pelaksanaan tri dharma perguruan tinggi. Masalah yang sering terjadi saat ini terjadinya ketidak adilan dalam pemberian beban SKS pada masing-masing dosen sehingga menyulitkan bagian Penjamin Mutu untuk menentukan mana dosen yang telah memiliki beban SKS berlebih dan mana dosen yang mempunyai kekurangan beban SKS. Masalah yang lain adalah kurang nya minat dosen untuk mengurus kepangkatan (jabatan fungsional) sehingga menyulitkan dosen untuk bisa mengembangkan diri menjadi dosen yang berkualitas. Untuk itu perlu rasanya peneliti menambahkan satu variabel lagi dalam menentukan baik tidak nya mutu dosen dalam menjalankan Tri Dharma Perguruan Tinggi. Dengan 
penerapan aplikasi ini nantinya diharapkan setiap dosen telah mempunyai beban SKS yang cukup yaitu sebanyak 12 SKS, telah mempunyai jabatan fungsional dan mempermudah setiap dosen untuk mendapatkan sertifikasi dosen.

Pengukuran kinerja dosen diperlukan untuk mengetahui apakah tugas dan tanggung jawab dosen sudah sesuai dengan Tri Dharma Perguruan Tinggi. Hasil dari pengukuran kinerja dosen tersebut dapat dijadikan sebagai acuan dan peniliaian bagi dosen untuk melihat tingkat pencapaian kinerjanya. Oleh karena itu diperlukan aplikasi pengukuran indeks kinerja dosen yang dapat membantu dosen dan bagian kepegawaian untuk melihat kinerja dan menghitung nilai yang dikumpulkan untuk pengajuan kenaikan pangkat.

Penelitian ini ingin mengetahui hasil yang didapat dari penerapan dan perhitungan menggunakan logika Fuzzy, juga membantu evaluasi Dosen pada bidang pengendali mutu. Penelitian ini bertujuan menerapkan Metode Mamdani untuk mendapatkan nilai optimasi fungsi dengan cepat dalam penilaian kinerja dosen. Metode Mamdani sering juga dikenal dengan nama Metode MaxMin. Metode ini diperkenalkan oleh Ebrahim Mamdani pada tahun 1975. Untuk mendapatkan output, diperlukan 4 tahapan: 1 . Pembentukan himpunan fuzzy;2. Aplikasi fungsi implikasi (aturan);3. Komposisi aturan;4. Penegasan (deffuzy).
Fuzzy adalah sebuah sistem kontrol untuk pemecahan masalah berbasis komputer berbasis akuisisi data. Logika fuzzy mempunyai dua kemungkinan seperti 0 atau 1, "benar" atau "salah". Meskipun nilai keanggotaannya sama namun fuzzy mampu membedakaan nilai dari keanggotaan tersebut dari bobot yang dimiliki. Logika fuzzy merupakan sebuah logika yang memiliki kekaburan atau kesamaran (fuzzyness) antara benar atau salah. Dalam teori logika fuzzy, sebuah nilai bisa bernilai benar atau salah secara bersamaan namun berapa besar kebenaran atau kesalahan suatu nilai tergantung kepada bobot/derajat keanggotaan yang dimilikinya.

Agar penyusunan penelitian ini tidak keluar dari pokok permasalahan yang dirumuskan, maka ruang lingkup pembahasan dibatasi pada beberapa kriteria yang menjadi ukuran untuk evaluasi kinerja dosen. Kriteria tersebut antara lain:
a. Pendidikan dan pengajaran.
b. Penelitian dan publikasi.
c. Pengabdian masyarakat.
d. Jabatan Fungsional.

\section{METODE PENELITIAN}

Metodologi penelitian dan kerangka kerja penelitian. Kerangka kerja ini merupakan langkah-langkah yang akan dilakukan dalam penyelesaian masalah yang akan dibahas. Adapun kerangka kerja penelitian ini dapat di gambarkan pada: 


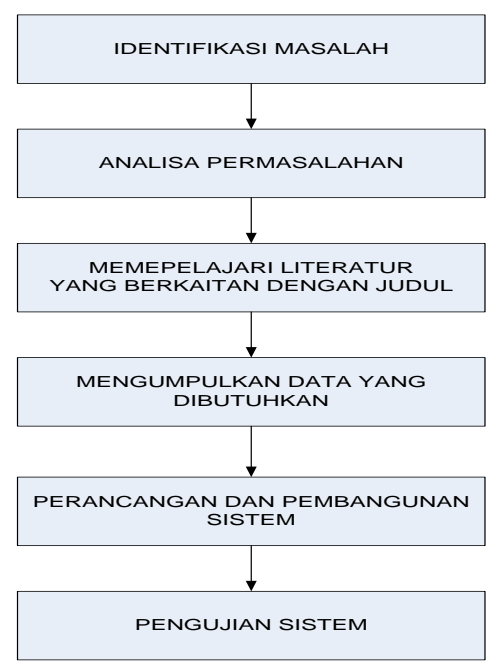

Gambar 1: Kerangka Kerja

Berdasarkan kerangka kerja pada gambar 1 maka masing-masing langkahnya dapat diuraikan seperti berikut ini :

\section{Identifikasi Masalah}

Pada tahap ini dirumuskan masalah yang akan menjadi objek penelitian. Perumusan masalah dilakukan untuk menentukan masalah apa saja yang terdapat pada objek penelitian serta memberikan batasan dari permasalahan yang akan diteliti.

Penelitian ini ingin mengetahui hasil yang didapat dari penerapan dan perhitungan menggunakan logika Fuzzy, juga membantu evaluasi Dosen pada bidang pengendali mutu. Penelitian ini bertujuan menerapkan Metode Mamdani untuk mendapatkan nilai optimasi fungsi dengan cepat dalam penilaian kinerja dosen. Maka ruang lingkup pembahasan dibatasi pada beberapa kriteria yang menjadi ukuran untuk evaluasi kinerja dosen. Kriteria tersebut antara lain: Pendidikan dan pengajaran, Penelitian dan publikasi, Pengabdian masyarakat, Jabatan Fungsional.

\section{Analisa Permasalahan}

Langkah analisis masalah adalah langkah untuk dapat memahami masalah yang telah ditentukan ruang lingkup atau batasannya. Dengan menganalisa masalah yang telah ditentukan tersebut, maka diharapkan masalah dapat dipahami dengan baik. Teknik analisis yang digunakan dapat dilakukan dengan beberapa tahap berikut: (1) tahap identify yaitu: mengidentifikasi permasalahan yang terjadi, (2) tahap understand yaitu: memahami lebih lanjut tentang permasalahan yang ada dengan cara melakukan pengumpulan data yang dibutuhkan, (3) tahap analyze yaitu: mencari kelemahankelemahan sistem yang ada dan 
mengumpulkan informasi tentang kebutuhan-kebutuhan lebih lanjut yang diperlukan oleh pemakai.

Masalah yang dihadapi adalah bagaimana mengembangkan dan menyempurnakan sistem yang dipakai dengan menggunakan metode fuzzy inference system (FIS) mamdani. Sehingga membantu evaluasi Dosen pada bidang pengendali mutu

\section{Mempelajari Literatur yang} berkaitan dengan judul

Berdasarkan pemahaman dari masalah, maka ditentukan tujuan yang akan dicapai dari penulisan ini. Pada tujuan ini ditentukan target yang dicapai, terutama yang dapat mengatasi masalahmasalah yang ada. Setelah masalah dianalisa, maka dipelajari literatur yang berhubungan dengan permasalahan. Kemudian literatur- literatur yang dipelajari tersebut diseleksi untuk dapat ditentukan literatur mana yang akan digunakan dalam penelitian ini. Sumber literatur didapatkan dari perpustakaan, jurnal, artikel, yang membahas tentang Logika Fuzzy Logic, Fuzzy Inference System (FIS) metode Mamdani, dan bahan bacaan lain yang mendukung penelitian.

\section{Mengumpulkan data - data yang dibutuhkan}

Dalam tahap pengumpulan data dilakukan beberapa cara yaitu :

a. Observasi, Yaitu pengamatan secara langsung ditempat penelitian sehingga permasalahan yang ada dapat diketahui secara jelas b. Wawancara, dilakukan dengan pihak yang terkait yang bertujuan untuk mendapatkan data atau informasi yang dibutuhkan. Pada penelitian ini pihak yang di wawancarai adalah bagian penjaminan mutu, dosen dan pimpinan.

c. Melakukan studi pustaka dengan membaca buku- buku yang menunjang untuk dapat menganalisa data dan informasi yang didapat.

5. Perancangan dan

Pembangunan sistem

Tahap selanjutnya adalah merancang sistem. Pada perancangan sistem akan dilakukan beberapa kegiatan sebagai berikut :

\section{a. Perancangan Model}

Model merupakan gambaran dari solusi yang akan dihasilkan, sehingga dari model yang ada, kita dapat mengetahui dan menggambarkan apa yang akan dihasilkan dari proses yang dilakukan nantinya. Dengan demikian kita mempunyai pedoman didalam merancang suatu sistem.

\section{b. Perancangan Input}

Berdasarkan teknik-teknik yang digunakan di atas, maka dapat dilakukan perancangan input dari sistem ini sehingga proses berikutnya dapat dilakukan berdasarkan perancangan input tersebut.

\section{c. Perancangan Rule}

Berdasarkan perancangan model dan perancangan input, maka langkah berikutnya akan di lakukan perancangaan dari rule-rule yang akan digunakan didalam penentuan 
kinerja dosen dalam menjalankan Tri Dharma Perguruan Tinggi dengan batasan-batasan yang sudah ditentukan. Sehingga dengan adanya rule-rule ini dapat membantu untuk metode fuzzy logic.

Setelah kita melakukan perancangan sistem maka tahap selanjutnya adalah pembangunan sistem berdasarkan rancangan sistem yang telah kita buat.

\section{Pengujian sistem}

Tahap berikutnya setelah perancangan dan pembangunan sistem adalah pengujian sistem, hal ini dilakukan untuk melihat sejauh mana fuzzy mamdani ini mampu memecahkan permasalahan, Pada tahap pengujian sistem penulis mengimplementasikan model dan hasil perancangan sistem menggunakan software matlab.

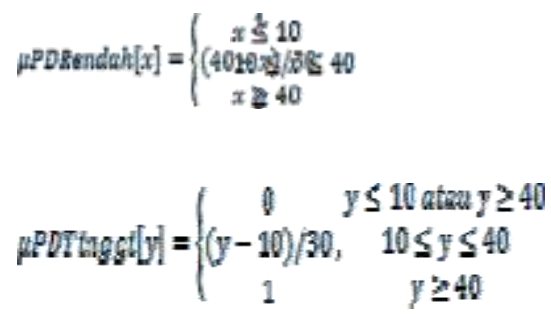

Pengujian dilakukan mengambil sample data pendidikan, penelitian, pengabdian masyarakat, dan jabatan fungsional. Hasil yang didapat kemudian dievaluasi berdasarkan perhitungan kinerja dosen apakah sudah sesuai dengan hasil yang ingin dicapai yaitu kinerja dosen dalam menjalankan Tri Dharma Perguruan Tinggi.

\section{HASIL DAN PEMBAHASAN}

Dalam pembentukan himpunan fuzzy, terdapat 4 variabel input dan 1 variabel output, dengan penjelasan sebagai berikut:

1. Variabel Pendidikan dan pengajaran merupakan variabel input, memiliki 2 himpunan fuzzy, yaitu rendah dan tinggi. Fungsi keanggotaanya

2. Variabel Penelitian yang merupakan variabel input, memiliki 2 himpunan fuzzy, yaitu rendah, dan tinggi.

Fungsi keanggotaanya:

$$
\begin{aligned}
& \mu \text { PLRendah }[x]=\left\{\begin{array}{cc}
1 & x \leq 5 \\
(35-x) / 30, & \leq x \leq 35 \\
0 & x \geq 35
\end{array}\right. \\
& \mu P L T \text { ingst }[y]=\left\{\begin{array}{cc}
0 & y \leq \mathbf{5} \\
(y-5) / 30,5 \leq y \leq \$ 5 \\
1 & y \geq 35
\end{array}\right.
\end{aligned}
$$

3. Variabel Pengabdian kepada masyarakat yang merupakan variabel input, 
memiliki 2 himpunan fuzzy, yaitu rendah, dan tinggi.

Fungsi keanggotaanya:

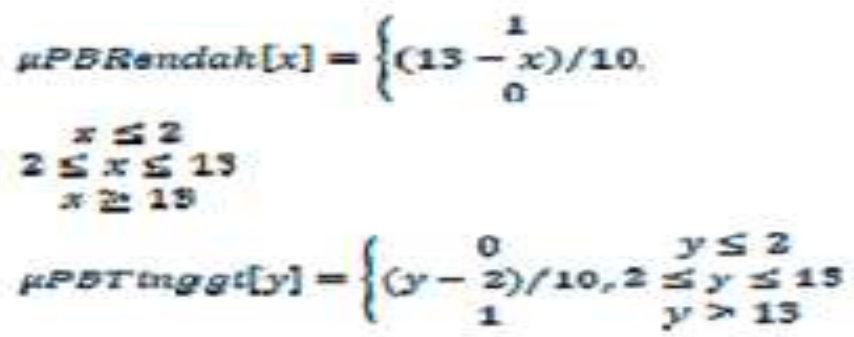

4. Variabel Jabatan Fungsional dosen yang merupakan variabel input, memiliki 2 himpunan fuzzy, yaitu rendah, dan tinggi

Fungsi keanggotaanya:

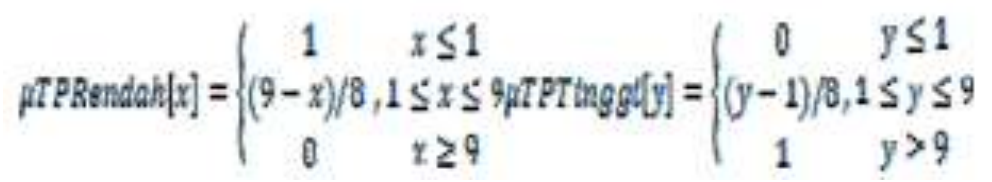

5. Nilai dosen merupakan output variabel, terdiri dari 3 himpunan fuzzy, yaitu: kurang, cukup, dan baik.

$$
\begin{aligned}
& \text { pNDkurang }[x]=\left\{\begin{array}{cc}
1 & x \leq 10 \\
(50-x) / 40, & 10 \leq x \leq 50 \\
0 & x \geq 50
\end{array}\right. \\
& \text { a.NDCuhrp }[y]=\left\{\begin{array}{cc}
0 & y \leq 10 \text { atou } y \geq 90 \\
(y-50) / 40, & 20 \leq y \leq 50 \\
(90-y) / 40 & 50 \leq y \leq 90
\end{array}\right. \\
& \mu N D B a i k[z]=\left\{\begin{array}{cc}
0 & z \leq 90 \\
(z-90) / 40,50 \leq & z \leq 90 \\
1 & z \geq 90
\end{array}\right.
\end{aligned}
$$

Input dari proses Defuzzifikasi adalah suatu himpunan fuzzy yang diperoleh dari komposisi aturan-aturan fuzzy, sedangkan output yang dihasilkan merupakan suatu bilangan pada domain himpunan fuzzy tersebut. Sehingga jika diberikan suatu himpunan fuzzy dalam range tertentu, maka harus diambil suatu nilai crisp tertentu sebagai output. Metode defuzzifikasi pada penelitian ini menggunakan metode centroid. Secara umum rumusnya adalah 


$$
\begin{aligned}
& z^{*}=\frac{\int_{z}^{D} z \mu(z) d z}{\int_{z}^{1} \mu(z) d z}, \text { untuk variabel kontinu, atau: } \\
& z^{*}=\frac{\sum_{j=1}^{n} z_{j} \mu\left(z_{j}\right)}{\sum_{j=1}^{n} \mu\left(z_{j}\right)}, \text { untuk variabel diskret }
\end{aligned}
$$

\section{KESIMPULAN}

Berdasarkan hasil penelitian dan pembahasan yang disampaikan pada bagian sebelumnya, maka dapat ditarik beberapa kesimpulan Implementasi Fuzzy Inference System (FIS) diterapkan dengan cara mengidentifikasi parameterparameter masukan dalam proses fuzzification lalu parameterparameter tersebut di masukkan dalam rules yang terbentuk dari proses inference setelah itu dilakukan proses defuzzification yaitu menghitung rules dan sample data dengan rumus Mamdani sehingga mendapatkan hasil deteksi.

\section{SARAN}

Ada beberapa hal yang perlu disampaikan agar menjadi bahan pertimbangan untuk melengkapi penelitian dimasa mendatang. Halhal tersebut diungkapkan dalam bentuk saran seperti berikut:

a. Jika diperlukan, sistem Penilaian Mutu Kinerja Dosen Berbasis Fuzzy Logic ini dapat dikembangkan lebih lanjut dengan menggunakan kombinasi dari hasil sistem yang berjalan agar lebih akurat data yang dihasilkan.

b. Aplikasi pendukung sistem
Penilaian Mutu Kinerja Dosen Berbasis Fuzzy Logic dapat dikembangkan agar tidak hanya menjadi prototype saja, melainkan diimplementasikan dalam proses pendeteksian secara nyata agar dapat memberikan kemudahan dalam proses.

\section{DAFTAR PUSTAKA}

1. Andreas Widiyantoro, T. S. (2014). Menerapkan Logika Fuzzy Mamdani Untuk Menentukan Harga Jual Batik. Techno.COM, Vol. 13, No. 2, Mei 2014: 69-74 (pp. 69-74). Techno.COM.

2. Efraim Turban, dkk, (2005) Decision Support System and Intelligent System $7^{\text {th }} \mathrm{Ed}$, Pearson Eduction Inc.

3. Kusumadewi, S. (2006). Artificial Iinteligence (Teknik dan Aplikasinya). Yogjakarta: Graha Ilmu.

4. Ross, T. J. (2010). Fuzzy Logic with Engineering Applications, Third Edition. University of New Mexico, USA: John Wiley \& Sons, Ltd. ISBN: 978-0-47074376-8.

5. T. Sutojo, M. E. (2011). Kecerdasan Buatan. Yogjakarta: Andi Offset. 